\title{
EnVIROnnfeTtA
}

Subscriber access provided by CORNELL UNIVERSITY LIBRARY

Policy Analysis

\section{Assessing urban wastewater system upgrades using integrated modeling, life cycle analysis and shadow pricing}

W. ACS Publications

Environmental Science \& Technology is published by the American Chemical Society. 1155 Sixteenth Street N.W., Washington, DC 20036

Published by American Chemical Society. Copyright (c) American Chemical Society. However, no copyright claim is made to original U.S. Government works, or works produced by employees of any Commonwealth realm Crown government in the course of their duties. 


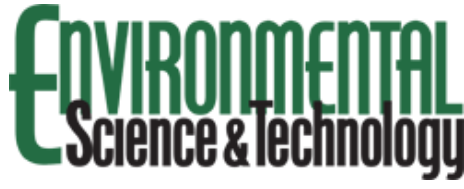

Subscriber access provided by CORNELL UNIVERSITY LIBRARY

Antonia Hadjimichael, Serni Morera, Lorenzo Benedetti, Tony

Flameling, LLUIS COROMINAS, Stefan Weijers, and Joaquim Comas

Environ. Sci. Technol., Just Accepted Manuscript - DOI:

10.1021/acs.est.5b05845 • Publication Date (Web): 30 Sep 2016

Downloaded from http://pubs.acs.org on October 3, 2016 


\section{EnVIROnNAETAR}

\section{Just Accepted}

"Just Accepted" manuscripts have been peer-reviewed and accepted for publication. They are online prior to technical editing, formatting for publication and author proofing. The American $\mathrm{Cr}$ Society provides "Just Accepted" as a free service to the research community to exped dissemination of scientific material as soon as possible after acceptance. "Just Accepted" mant appear in full in PDF format accompanied by an HTML abstract. "Just Accepted" manuscripts hav 


\section{EnVIROnNAETTAL}

Subscriber access provided by CORNELL UNIVERSITY LIBRARY fully peer reviewed, but should not be considered the official version of record. They are accessib readers and citable by the Digital Object Identifier (DOI®). "Just Accepted" is an optional service to authors. Therefore, the "Just Accepted" Web site may not include all articles that will be pu in the journal. After a manuscript is technically edited and formatted, it will be removed from th Accepted" Web site and published as an ASAP article. Note that technical editing may introduce changes to the manuscript text and/or graphics which could affect content, and all legal disc 


\section{EnVIROnNAETTAL}

Subscriber access provided by CORNELL UNIVERSITY LIBRARY and ethical guidelines that apply to the journal pertain. ACS cannot be held responsible for or consequences arising from the use of information contained in these "Just Accepted" manu 
SOEnvironmental Science \& Technology

\section{VALUES}

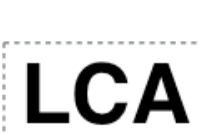

Impact

category

weights $(€)$

Emissions

to air

Loads coming from upstream

Catchment

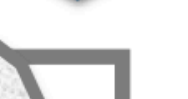

Materials

Sludge dewatering \& incineration

Sludge

cso

Eindhoven WWTP

Materials

Dommel river

cso ACS Paragystep pleqsuedaries nnment 


\section{Assessing urban wastewater system upgrades}

\section{2 using integrated modeling, life cycle analysis and}

\section{shadow pricing}

4 Antonia Hadjimichael ${ }^{1}$, Serni Morera ${ }^{1}$, Lorenzo Benedetti ${ }^{2}$, Tony Flameling ${ }^{3}$, Lluís Corominas $^{4}$,

${ }^{1}$ Laboratory of Chemical and Environmental Engineering (LEQUIA), Institute of the Environment, Universitat de Girona, Campus Montilivi, s/n, 17071 Girona (Spain)

${ }^{2}$ WATERWAYS d.o.o., Gornji Vukojevac 10A, 44272 Lekenik, Croatia

${ }^{4}$ Catalan Institute for Water Research (ICRA), Emili Grahit 101, Parc Científic i Tecnològic de 
16 This study assesses the environmental impacts of four measures proposed for upgrading of the

17 urban wastewater system of Eindhoven and the Dommel River in the Netherlands, against the

18 base-case "do-nothing" option. The measures aim to reduce the overall environmental impact of

19 the Eindhoven urban wastewater system (UWS) by targeting river dissolved oxygen depletion

20 and ammonia peaks, reducing combined sewer overflows and enhancing nutrient removal. The

21 measures are evaluated using a life cycle analysis with the boundaries including the receiving

22 river section by means of an integrated model of the UWS. An uncertainty analysis of the

23 estimated impacts has been performed to support the outcomes. The study also uses the

24 economic concept of shadow prices to assign relative weights of socio-economic importance to

25 the estimated life cycle impacts. This novel integration of tools complements the assessments of

26 this UWS with the inclusion of long-term global environmental impacts and the investigation of

27 trade-offs between different environmental impacts through a single monetary unit. The results

28 support the selection of deeper clarifiers as the most environmentally beneficial measure for 29 upgrade.

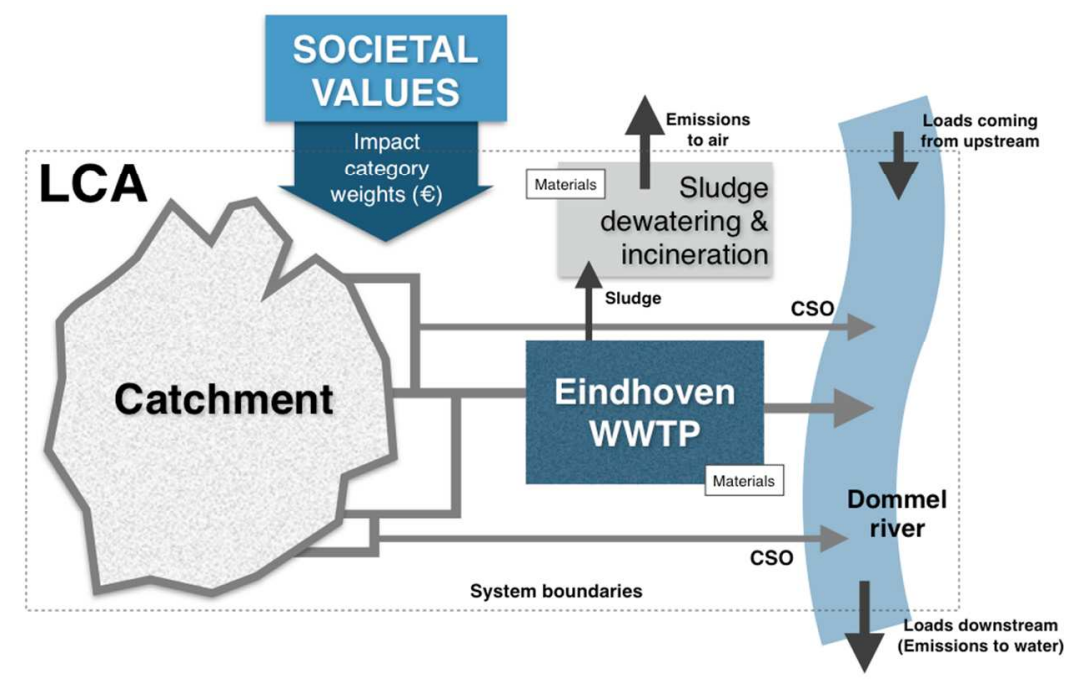

Abstract art 
31 Sustainable development has now been adopted as an overarching goal of all economic and

32 social development by multiple United Nations agencies, individual nations, local governments

33 and corporations ${ }^{1}$. Prerequisites for this are decisions encompassing technical economic, social

34 and environmental considerations ${ }^{2}$. For urban wastewater systems (UWSs) management this

35 integration can only be achieved through the integration of state-of-the-art tools that support

36 decision making.

37 Water management agencies are already conducting several studies to ensure the operation of

38 the UWS adheres to these principles (for example the KALLISTO project ${ }^{3-6}$ by the Waterschap

39 de Dommel (WdD)). These studies have evaluated the cost-effectiveness and the technical

40 performance of various proposed UWS upgrades, often looking at the ecological improvement of

41 the receiving water body. An important tool in these analyses has been integrated modeling,

42 encompassing the whole UWS and receiving medium and enabling dynamic assessments of the

43 systems at hand ${ }^{3-8}$. Despite the great strides made during these assessments, some aspects often

44 remain unaddressed - primarily global and long-term environmental impacts.

45 Life Cycle Analysis (LCA) is a technique to quantify the impacts associated with all the stages

46 of a product, service or process from cradle-to-grave, in order to evaluate the environmental

47 impact of its entire life cycle ${ }^{9}$. The application of LCA allows for the assessment of secondary,

48 global impacts brought about by the proposed measures for UWS upgrading. There have been

49 multiple examples of the LCA method being applied to UWSs, several of which have expanded

50 on the conventional wastewater treatment plant (WWTP) boundaries to include other parts of the

51 UWS $^{10,11}$ (for example, [12-14]). To the best knowledge of the authors, no LCA on the UWS has

52 yet employed a deterministic integrated model taking into account hydraulics as well as 
53 biochemical processes of the whole system (sewer system, WWTP and receiving water body).

54 For this purpose we employ an integrated model of the UWS - already used in previous studies ${ }^{3-6}$

55 - which has shown to be a powerful tool to analyse and evaluate the proposed measures. This

56 allows for a more integrative analysis as well as climatic and seasonal variations in the influent

57 composition. The river model allows for the consideration of its functions and its capacity to

58 dilute and uptake the discharged loads. Integrated modeling also provides the ability to

59 investigate the dynamic effect of operational changes and upgrades on the assessment of the

60 LCA impact categories.

61 Weighting is an optional step during a LCA and it can be used to include a prioritisation of the

62 various impact categories and convert and aggregate the results into a single indicator. It is

63 thought to be subjective and has therefore always been a controversial step of the LCA technique

64 as it reflects personal values in the social, ethical and political fields ${ }^{15-17}$. Despite their

65 subjectivity, these value-choices may be more relevant to the decision-making process as they

66 can simplify and aggregate impacts. Weighting can be either quantitative or qualitative ${ }^{18,19}$ and

67 authors have suggested that methods based on monetary values or the judgement of an expert

68 panel are the most promising ${ }^{20}$. Currency appears to be a unit that can be easily integrated by

69 decision-makers in the decision process and be contrasted against other indicators ${ }^{19,21}$. It is also a

70 unit that is easily understandable and communicable by a wide range of decision-makers ${ }^{22}$.

71 Valuation aims to express the value society puts on them in monetary terms for purposes of

72 assessment and internalisation ${ }^{23}$. By attaching a value on an emission the estimated

73 environmental damage (or 'cost') can be an indicator of the environmental losses for the society

74 regarding its present and future emission goals ${ }^{24,25}$. This a largely vague undertaking, mainly

75 hindered by the fact that in many cases no market exists for elements such as water quality or 
76 pollution ${ }^{1}$. Various methods for valuation of externalities have been developed in the field of

77 economic theory ${ }^{19}$ with the most common technique appearing in water resources literature being

78 the Contingent Valuation Method (CVM). CVM is considered by many authors as a consolidated

79 method, given its numerous practical applications ${ }^{26-28}$. Nonetheless, there is no unanimous

80 consensus on the validity of this methodology in the scientific community as a tool for the

81 valuation of environmental goods ${ }^{29-32}$. One of the most common criticisms of the CVM and

82 other survey-based methods is that people are often responding to a survey and not a budget

83 constraint, which tends to bias positively their support of abatement $\operatorname{costs}^{33}$. Shadow pricing

84 offers an alternative approach to this for the valuation of environmental externalities (in this case

85 pollution), among other purposes ${ }^{32,34}$. The "desktop" shadow price estimation has very low costs,

86 compared to traditional surveying methods and, for applications in a policy context, decision

87 makers have found approaches based on the premise that government represents society more

88 promising ${ }^{19}$. Among various other uses, authors have proposed the use of shadow prices to

89 assign relative weights to environmental impacts identified in environmental analyses such as

$90 \mathrm{LCAs}^{23}$. The values used in this study were derived from abatement and damage costs related to

91 each environmental impact for the country of the Netherlands.

92 The objective of this paper is to employ a novel approach to assess measures for UWS

93 upgrading. The measures are evaluated by integrating a deterministic model with LCA and the

94 application of weights of relative abatement prioritisation to the estimated impacts. The utility of

95 this integrated approach is illustrated with the case study of the Eindhoven UWS. The boundary

96 of the analysis is extended to include the adjacent river section of the Eindhoven UWS, i.e. the

97 river Dommel, taking into account its dilution and purification capacity. With this new

98 application of LCA and weighting through shadow prices, we present a novel integration of 
99 methods to account for sustainable development, compared to traditional approaches. The 100 application presented in this paper aims to complement the other studies performed by the 101 managing authority in Eindhoven (WdD) to decide on upgrades for the UWS while adhering to 102 the principles of sustainable development.

\section{CASE STUDY: EINDHOVEN URBAN WASTEWATER SYSTEM}

105

The studied system is the Eindhoven WWTP and its collection system, located in the southeast of the Netherlands. The Eindhoven WWTP treats the wastewater of 750,000 inhabitant equivalents (IE) with a design load of $136 \mathrm{~g}$ COD/day/IE. The received wastewater is treated in three parallel lines, each consisting of a primary settler, a biological tank and four secondary 109 settlers. The plant has a modified UCT (University Cape Town) configuration for biological 110 chemical oxygen demand (COD), nitrogen $(\mathrm{N})$ and phosphorous $(\mathrm{P})$ removal. The proposed 111 measures to be evaluated and their principal targets (enhance nutrient removal, reduce CSOs and 112 reduce river DO depletion) are summarised in Table 1.

113 Measure A involves the deepening of the secondary clarifiers of the Eindhoven WWTP. This 114 has significant improvements on smoothing ammonia peaks and the average nitrate removal, by 115 increasing the biological capacity of the plant by allowing a higher sludge mass in the activated 116 sludge system. For measure B, the installation of newly developed in-stream aeration systems is 117 considered to aerate flowing surface water, increasing oxygen levels and thus improving river 118 water quality ${ }^{35}$. By tackling dissolved oxygen (DO) depletion the protection of critical river 119 fauna species is better ensured. For enhanced total nitrogen and phosphorus removal, Measure C 120 is proposed - the installation of a sand filter for effluent polishing. Finally, with the aim of 121 reducing the release of combined sewer overflows (CSOs) and prevent DO depletion, Measure D 
122 involves the construction of additional storage capacity in the Eindhoven collection system. A

123 more detailed description of the studied system and the proposed measures can be found in the

124 Supporting Information.

\begin{tabular}{|l|l|l|}
\hline Symbol & Measure & Target \\
\hline A & $\begin{array}{l}\text { Improvement to the WWTP by deepening the secondary } \\
\text { clarifiers }\end{array}$ & $\begin{array}{l}\text { Enhanced ammonium } \\
\text { removal }\end{array}$ \\
\hline B & $\begin{array}{l}\text { River quality improvement by installing in-stream } \\
\text { aeration stations in the Dommel River }\end{array}$ & $\begin{array}{l}\text { Reduce dissolved oxygen } \\
\text { (DO) depletion in the river }\end{array}$ \\
\hline C & $\begin{array}{l}\text { Construction of a tertiary sand filter as an add-on to the } \\
\text { WWTP }\end{array}$ & $\begin{array}{l}\text { Enhanced nitrate and } \\
\text { phosphorus removal }\end{array}$ \\
\hline D & $\begin{array}{l}\text { Construction of additional storage capacity as an add-on } \\
\text { to the combined sewer system }\end{array}$ & $\begin{array}{l}\text { Reduce combined sewer } \\
\text { overflows (CSOs) }\end{array}$ \\
\hline
\end{tabular}

Table 1 - Measures to be evaluated for application to the UWS IMPACTS

129 There are four main phases in an LCA analysis: Goal \& Scope Definition, Inventory Analysis, 130 Impact Assessment and Interpretation. Their application is described below, with the 131 Interpretation in the Results section. Weighting is applied during the Impact Assessment phase.

132 In this study we employ shadow prices to attach weights on the estimated impacts. Uncertainty 133 analyses were also performed, first on four of the critical parameters of the LCA to assess the 134 robustness of the impacts estimation, and secondly on the assumed shadow prices used as 135 weights. 


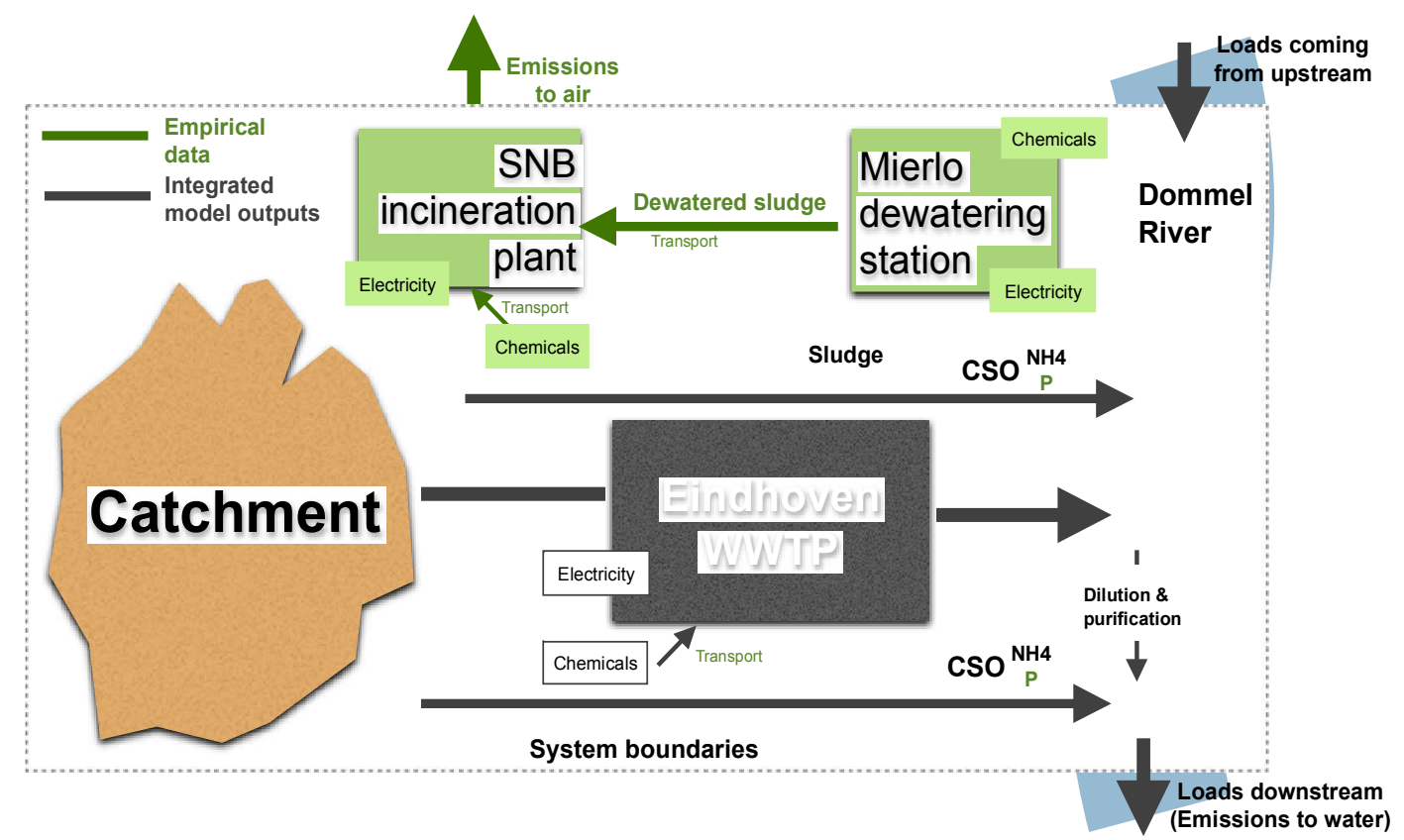

Figure 1 - System boundaries. For the Inventory Analysis: items in grey indicate model outputs; items in green indicate empirical data.

The goal of the LCA is to assess the environmental impacts caused by the current operation of

139 the Eindhoven UWS and to compare them against the estimated environmental impacts by each

140 of the proposed upgrading measures. The system boundaries include the catchment under study,

141 the sewer system with its CSOs, the wastewater treatment plant, chemicals and energy used

142 during the treatment, the river section within the catchment boundaries and discharged pollutant

143 loads (phosphorus, ammonium, nitrate) leaving the studied river section (Figure 1). Construction

144 of the WWTP and sewer systems have not been taken into account as they would be the same for

145 all measures as well as the base case. The lifespan and maintenance of mechanical equipment

146 and constructions of the proposed measures have also been included in the analysis.

147 For the sludge treatment, the dewatering installation at Mierlo and the sludge incineration

148 facility (SNB) were taken into account along with the chemicals and energy used at said

149 facilities. The transportation of chemicals and dewatered sludge to the incineration facility were 
150 also included. The functional unit is ten years of system operation treating approximately

$151546,550,190 \mathrm{~m}^{3}$ of wastewater in total. This allowed the inclusion of climatic variability over

152 that period as well as seasonal dynamics of influent wastewater.

153 Inventory analysis

154 The inventory data consist of: (i) inputs to the system (energy and chemical consumption and

155 transport); (ii) outputs from the system (emissions to air and water); (iii) inputs and outputs of 156 sludge treatment; (iii) inputs and outputs of construction of each measure (materials used and

157 generated waste); and (v) infrastructure and equipment maintenance of each measure, presented

158 in Table 2 and Supporting Information Tables S1 (for sludge treatment), S2 (for construction of 159 each measure) and S3 (for the construction of the pumps needed in Measure A). The sludge 160 treatment data were provided by the $\mathrm{WdD}^{36}$ and the $\mathrm{SNB}$ incineration facility ${ }^{37}$ for the year 2013.

161 Information regarding the maintenance of infrastructure and equipment was provided by the 162 WdD. Regarding maintenance, the lifespan of constructed infrastructure and equipment was 163 taken into account. The lifespan of all mechanical equipment was assumed to be 15 years and 30 164 years for all civil constructions.

\begin{tabular}{|c|c|c|c|c|c|c|}
\hline & & Base case & A & B & C & D \\
\hline \multicolumn{7}{|l|}{ Inputs to the system } \\
\hline Aluminium sulphate, powder & \multirow{2}{*}{ ton } & 61,590 & 37,708 & 61,716 & 68,555 & 63,380 \\
\hline Methanol (carbon source) & & - & - & - & 17,266 & - \\
\hline Construction & - & - & $\begin{array}{l}12 \text { deeper } \\
\text { clarifiers }\end{array}$ & $\begin{array}{l}5 \text { aeration } \\
\text { stations }\end{array}$ & $\begin{array}{l}21 \text { sand } \\
\text { filter units }\end{array}$ & $\begin{array}{l}10 \text { storage } \\
\text { tanks }\end{array}$ \\
\hline Construction maintenance cycle & years & - & $\begin{array}{l}30 \text { for clarifiers } \\
15 \text { for pumps }\end{array}$ & 15 & 30 & 30 \\
\hline Electricity, medium voltage & MWh & 236,376 & 232,756 & 237,935 & 236,408 & 236,555 \\
\hline \multicolumn{7}{|c|}{ Outputs to water at the end of the river reach } \\
\hline Phosphorus, total & \multirow{3}{*}{ ton } & 518 & 554 & 518 & 461 & 500 \\
\hline Ammonium & & 1,802 & 1,307 & 1,794 & 1,802 & 1,770 \\
\hline Nitrate & & 3,127 & 2,834 & 3,128 & 2,787 & 3,156 \\
\hline \multicolumn{7}{|l|}{ Transport } \\
\hline Transport of aluminium sulphate & \multirow{2}{*}{ Mtkm } & 3.39 & 2.07 & 3.39 & 3.77 & 3.49 \\
\hline Transport of methanol & & - & - & - & 0.95 & - \\
\hline Sludge for treatment & $\mathrm{Mm}^{3}$ & 5.80 & 5.78 & 5.79 & 5.84 & 5.93 \\
\hline
\end{tabular}


Table 2 - Inventory table for system inputs and outputs. The 10-year operation of base case and the four evaluated measures are presented along with their construction. Inventory table for sludge treatment provided in Table S1 of supporting information. Inventory tables for construction provided in Tables S2 and S3 of supporting information.

The data regarding outputs to water, electricity use and sludge production were obtained using the integrated UWS model. The model has been implemented in the WEST® simulation software (www.mikepoweredbydhi.com) and has been calibrated, validated and extensively used for measure evaluations in previous studies within the KALLISTO project ${ }^{3-6}$. The UWS integrated model used is made up of the integration of three separate models - for the catchment and sewer system, the WWTP and the river. The hydraulics of the sewer system were represented as tanks-in-series in a detailed hydrodynamic sewer model built in InfoWorks version 9.5 (www.innovyze.com). A conceptual catchment model based on empirical relationships was developed to generate the influent water quality, as water quality modules in sewer models are still not considered sufficiently reliable ${ }^{5,38}$. Event mean concentrations were applied for the CSO outputs into the river, derived from two years of monitoring data of CSOs. The ammonium $\left(\mathrm{NH}_{4}{ }^{+}\right)$loads were given by the model, whereas the $\mathrm{P}$ loads were estimated based on empirical measurements. The WWTP was modeled using the ASM2d biokinetic model modified by Gernaey and Jørgensen $(2004)^{39}$ and Takács et al. (1991) ${ }^{40}$ for settler modeling. A surface water model has been set up to represent the Dommel River and its main tributaries as tanks-in-series, using the Duflow Modeling Tool (Stowa/MX.Systems 2004). The DUFLOW model is based on the one-dimensional partial differential equation that describes non-stationary flow in open channels and allows for the construction of 1D-hydrodynamic models including substance transport and processes. 70 river sections and 34 discharge points, representing (clusters of) CSOs and the WWTP effluent are combined together to describe the Dommel River system. The processes in the river model with DO and ammonium as state variables include 
191 BOD decay, re-aeration, plant production and respiration, nitrification and settling of particulate 192 organic matter ${ }^{5}$. The equations of the implemented model are described by ordinary differential 193 equations and are solved with the use of the numerical variable step size VODE solver included

194 in WEST ${ }^{\circledR}$. For each of the measures and the base case the integrated model is simulating the 195 climatic and influent variability occurring in the system for the duration of ten years ${ }^{5}$. The ten196 year time series was developed using monitoring data of precipitation, sewer water levels and 197 flow, and water quality. A description of the development and calibration of the integrated UWS 198 model and the monitoring data used is provided in extensive detail Langeveld et al. $(2013)^{5}$.

199 The outputs to water are the net loads released to the environment at end of the studied reach 200 from the WWTP and CSOs. In this manner, the purification capacity of the receiving water is 201 taken into account in the estimated emissions. The performance of each of the measures with 202 regards to their principal targets (enhance nutrient removal, reduce CSOs, reduce river DO 203 depletion) can then be seen looking at the "Outputs to water at the end the river reach" (Table 2) 204 of each measure. The specific contribution of CSO events to the total outputs to water is 205 provided in detail in Table S4 of the supporting information for the base case and measure D 206 (storage tanks). The total contribution of CSO events to the ammonium loads emitted appeared 207 to be a small part of the overall emissions (less than $1.2 \%$ ), as well as the contribution of the 208 phosphorus loads ( $7.7 \%$ and $4.8 \%$ for the base case and measure D equivalently), attributed to 209 the fact that the total CSO volume is less than 4\% the WWTP effluent volume over 10 years. 210 Less clear are the benefits provided by the river aeration measure (B),and are discussed in more 211 detail in the Results and Discussion sections.

$212 \quad$ Impact assessment 
213 The data from the inventories were introduced into the Simapro® 8.0.3 software 214 (http://www.pre-sustainability.com/) which allows for the modeling and analysis of complete 215 LCAs in a systematic and transparent manner. To calculate the environmental impacts the 216 ReCiPe Midpoint (H) (1.09) ${ }^{41}$ method was used as it is based on the latest recommendations by

217 the LCA community ${ }^{42-44}$. Midpoint indicators were chosen over endpoint indicators as they 218 assume less uncertainty ${ }^{10}$ and they were considered sufficiently relevant by the decision maker of 219 this case study (WdD). The evaluated categories were: Climate Change (CC), Terrestrial 220 Acidification (TA), Freshwater Eutrophication (FE), Marine Eutrophication (ME), Human 221 Toxicity (HT), and Freshwater Ecotoxicity (FET). Short descriptions and units of equivalence for 222 each of the categories are supplied in Table S5 of the supporting information. The 223 characterisation factors for the major inputs and outputs are provided in Table S6 of the 224 supporting information. The electricity mix of the Netherlands for the year 2008 was used in the 225 impact assessment.

226 Uncertainty of inventory values

227 Four factors - use of aluminium sulphate, use of electricity, sludge production and effluent 228 loads (including ammonium, nitrate and phosphorus) - were selected to be studied in an 229 uncertainty analysis of the estimated impacts. A Monte Carlo analysis was performed in 230 Simapro ${ }^{\circledR} 8.0 .3$. The studied ranges for the four factors were from $-25 \%$ to $+25 \%$ of the applied 231 inventory value and assumed to be described by uniform distributions.

233 SHADOW PRICES FOR MONETARY WEIGHTING OF LCA IMPACT CATEGORIES

234 The estimation of shadow prices is most often based on an estimation of the damages caused 235 by the release of a pollutant (damage costs) or by calculating the costs associated to its avoidance 
236 and removal (abatement costs). The sets of prices used in this study were presented by de Bruyn

237 et al. ${ }^{23}$ for the ReCiPe midpoint impact categories and about 400 other pollutants for the

238 Netherlands. A wide range of literature sources was employed reporting on abatement and

239 damage costs to produce three sets of prices:

240 Set 1: Based on abatement costs, characterised at midpoint level

241 Set 2: Based on damage costs, estimated at ReCiPe midpoint level

242 Set 3: Based on implicit damage costs, estimated using ReCiPe endpoint factors

243 The exact shadow prices for 2008 for all three sets and short commentary on how they were

244 obtained are provided in the supporting information (Table S7). To convert the prices to their

2452014 equivalents, use was made of the Harmonised Index of Consumer Prices (HICP) for the

246 Eurozone. The HICP is an indicator of inflation and price stability compiled by the European

247 Central Bank for all countries of the European Union. The average annual rate of change of the

248 HICP for the Eurozone between 2008 and 2014 is provided in Table S8 of the supporting

249 information, while the resulting estimates of the three sets of shadow prices for 2014 in Table S9.

250 Due to the disparity between the values as well as possible theoretical preferences (e.g. damage

251 versus abatement) all three sets were applied for weighting, as a means of addressing the

252 uncertainty behind their estimations and their relative importance.

\section{$253 \underline{\text { RESULTS }}$}

\section{INTERPRETATION OF LCA RESULTS}

255 It is clear that the measure of deeper clarifiers (A) outperforms the base case and the other three 256 measures in its environmental impact in all categories besides Freshwater Eutrophication (FE)

257 (Figure 2). This can be attributed to the higher emission of phosphorus to water from this 258 measure. The FE category is also the only category where measure $\mathrm{C}$ (installation of a sand 259 filter) performs the best due to its reduction of effluent phosphorus. The generally bad 
performance of measure $\mathrm{C}$ in comparison with the other measures in all other categories can be attributed to its increased use of aluminium sulphate and methanol. Similarly, measure D

262 (construction of storage tanks) only performs better than the base case in the Marine

263 Eutrophication (ME) impact category by reducing the amount of CSOs released in the Dommel

264 River and thus the ammonium load. Measure B (in-stream aeration) does not appear to have any significant impact compared to the base-case scenario. Figure 3 presents in more detail the contributing factors to each impact category.

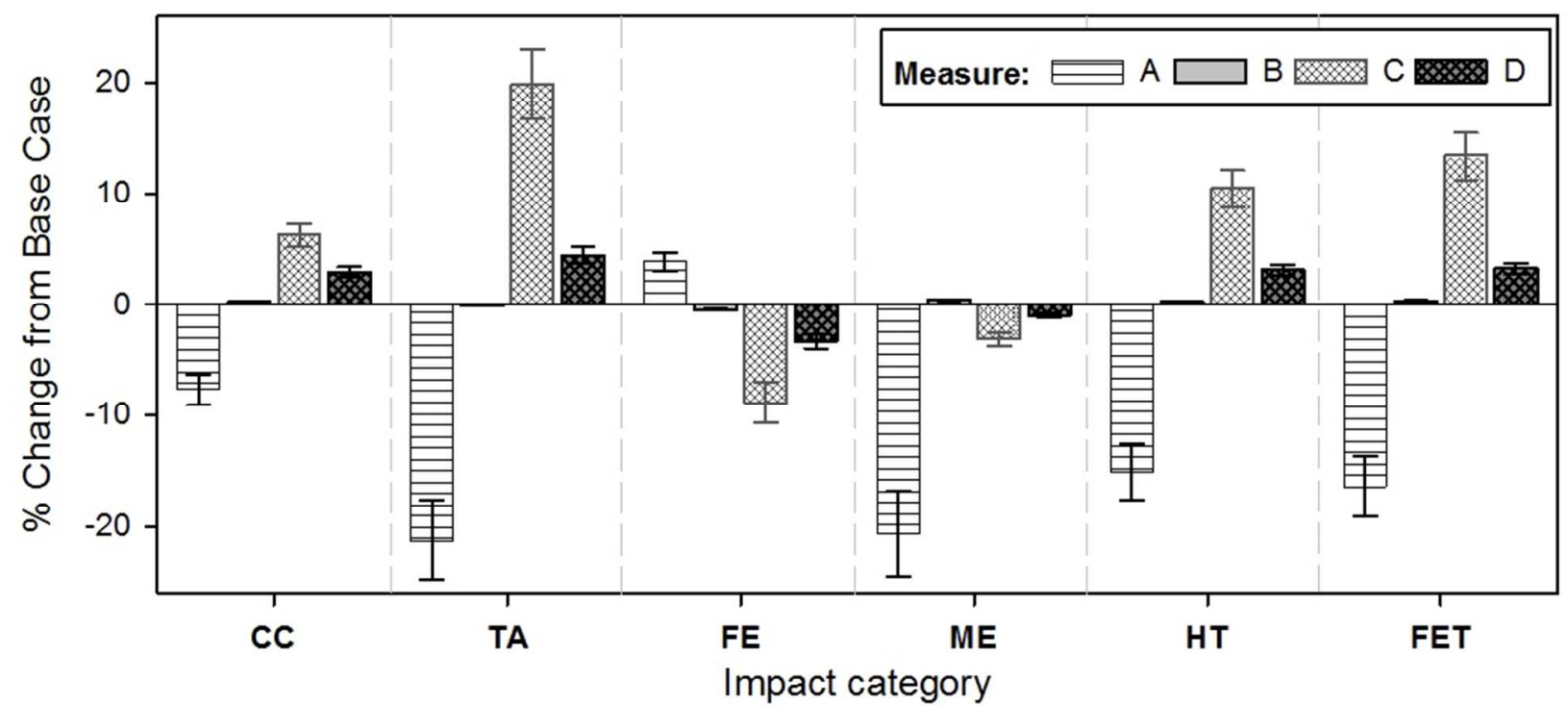

Figure 2 - Life Cycle Impact Assessment for ten years of system operation of the four assessed measures (A -

Deeper clarifiers, B - In-stream aeration, C - Sand filter, D - Storage tanks) compared to the base case scenario and across the six evaluated impact categories (CC - Climate Change, TA - Terrestrial Acidification, FE - Freshwater Eutrophication, ME - Marine Eutrophication, FET - Freshwater Ecotoxicity). The base case is supposed to be at a $0 \%$ of impacts. The error bars represent the $2.5^{\text {th }}$ and $97.5^{\text {th }}$ percentiles estimated during the uncertainty analysis, whereas the shaded bars represent the median.

Evidently and as expected, the effluent loads of all measures are the main contributing factor in

274 the Freshwater and Marine Eutrophication categories. Across all other categories, significant

275 effects appear to be caused by the use of aluminium sulphate, electricity and the production and

276 treatment of sludge. This makes clear a trade-off between the increased use of resources and

277 production of sludge and the reduction of phosphorus outputs to water, observed in all measures 
279 For measures $\mathrm{C}$ and $\mathrm{D}$ the increased use of materials results in a nitrate and ammonium reduction equivalently. For measure A, these emissions are reduced even with a decreased material use.

281 The trade-offs are less clear for measure B, as there is very little change in impacts when 282 compared to the base case. The use of methanol as a carbon source by measure $\mathrm{C}$ also appears to 283 have some effect, albeit lesser in comparison. In terms of construction, measure D causes the 284 highest impacts. Nevertheless, in general the construction and maintenance of measures appear 285 to have little relative effect on the total impacts in 10 years of operation (less than $2 \%$ ). The 286 effects of chemical transport seem to be of little significance (less than $0.5 \%$ ).

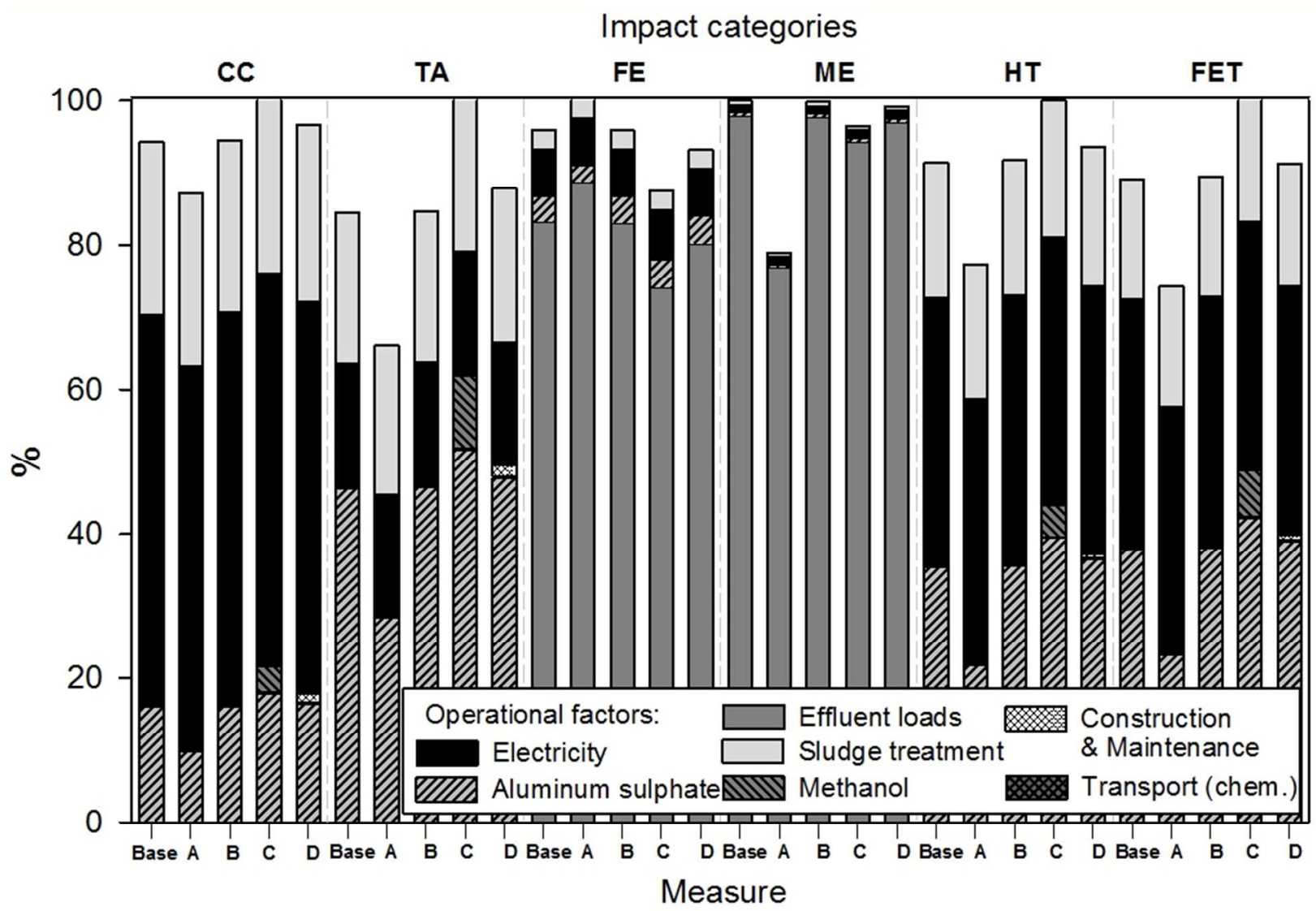

Figure 3 - Break-down of impacts for each of the investigated impact categories (CC - Climate Change, TA Terrestrial Acidification, FE - Freshwater Eutrophication, ME - Marine Eutrophication, FET - Freshwater Ecotoxicity) for base case and all measures (A - Deeper clarifiers, B - In-stream aeration, C - Sand filter, D Storage tanks) after ten years of system operation. 
After the uncertainty analysis of the four factors (use of aluminium sulphate, use of electricity, 289 sludge production and effluent loads), the $5^{\text {th }}$ and $95^{\text {th }}$ percentiles of all the calculated impacts are 290 presented for each of the measures across all categories in Figure 2. It can be seen by comparison 291 that the performance of Measure A remains consistently preferable in all impact categories, 292 barring Freshwater Eutrophication (FE).

\section{SHADOW PRICES FOR WEIGHTING OF LCA IMPACT CATEGORIES}

295 In order to attach weights of abatement and damage importance three sets of shadow prices were 296 then applied to the environmental impacts estimated in the impact assessment phase. For Set 1, 297 the estimated environmental costs can be an indicator of the environmental losses for the Dutch 298 society stemming from its present and future emission goals. For Sets 2 and 3, the estimated 299 environmental costs can be an indicator of the environmental losses for the Dutch society based 300 on the damage caused by each pollutant. It is important to clarify at this point that the estimated 301 environmental costs are originating and induced by the domestic, municipal and commercial 302 activities producing the wastewater in this catchment rather than the treatment itself. In addition, 303 the prices were estimated based on current abatement standards and therefore the results are 304 meaningful if and only if applied for marginal changes in operation, such as applications of new 305 measures.

306 This allows for the monetary quantification of the total life cycle impacts induced by each 307 measure. Figure 4 presents the total life cycle environmental costs for all measures and base 308 case. The error bars indicate the $2.5^{\text {th }}$ and $97.5^{\text {th }}$ percentiles of the induced environmental cost of 309 each measure including the uncertainty of the inventory values. The measure with the best 310 relative performance (Measure A) provides a reduction in environmental costs between 10 and 


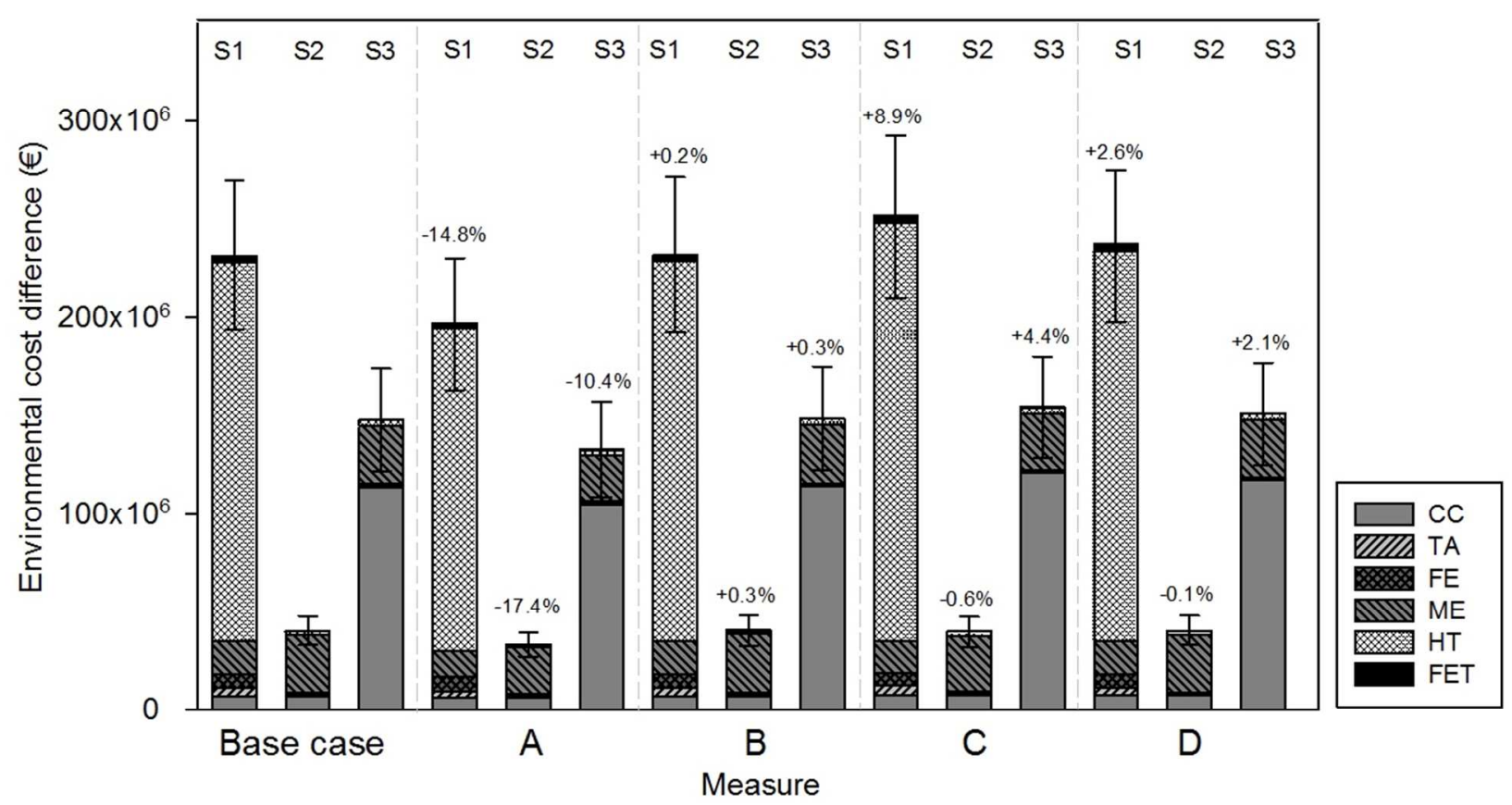

Figure 4 - Total Life Cycle environmental costs with respect to the emission goals of the Dutch society and their increase or reduction compared to the current base case $(0 €)$ after ten years of system operation. The error bars indicate the uncertainty on the total induced environmental cost of each measure (A - Deeper clarifiers, B - Instream aeration, $\mathrm{C}-$ Sand filter, $\mathrm{D}$ - Storage tanks). The total environmental cost is the sum of all the environmental impacts per category (CC - Climate Change, TA - Terrestrial Acidification, FE - Freshwater Eutrophication, ME Marine Eutrophication, FET - Freshwater Ecotoxicity). S1, S2 and S3 represent the shadow price sets Set 1 , Set 2 and Set 3 respectively.

314 As already mentioned, there seems to be an apparent trade-off between the environmental

315 improvement of the reduced phosphorus load released and the damages brought about by the use

316 of aluminium sulphate, electricity and sludge production. By use of shadow prices we present the

317 environmental damage induced per factor (input, output and emission) per $\mathrm{m}^{3}$ of treated

318 wastewater. Accordingly, the evaluation of this trade-off is facilitated by the use of a single

319 indicator. Table 3 lists the average environmental cost induced by each factor per $\mathrm{m}^{3}$ of treated

320 wastewater for the main inputs and outputs of this system. The numbers indicate a significantly

321 higher environmental cost induced by the use of electricity and aluminium sulphate and the 
322 production of sludge per $\mathrm{m}^{3}$ of wastewater, compared to the loads of phosphorus, ammonium and 323 nitrate released as emissions per $\mathrm{m}^{3}$ of wastewater.

324

325

326

327

328

329

330

331

332

333

334

335

336

337

338

339

\begin{tabular}{|l|l|l|l|}
\hline Factor & Unit & $\boldsymbol{€} /($ unit of factor) & (Total $€$ per factor)/(m $\mathbf{m}^{\mathbf{0}}$ of effluent) \\
\hline Output - Effluent phosphorus & ton & 5,364 & 0.0049 \\
\hline Output - Effluent ammonium & ton & 3,580 & 0.0295 \\
\hline Output - Effluent nitrate & ton & 1,021 & 0.0147 \\
\hline Input - Aluminium sulphate & ton & 562.2 & 0.0603 \\
\hline Input - Transport (chemicals) & tkm & 0.066 & 0.0003 \\
\hline Input - Methanol & ton & 296.5 & 0.0094 \\
\hline Input - Electricity & $\mathrm{kwh}$ & 0.223 & 0.0964 \\
\hline Sludge treatment & $\mathrm{m} 3$ & 4.371 & 0.0466 \\
\hline
\end{tabular}

Table 3 - Estimated average (across the three sets) of environmental monetary cost: per unit of input/output; and total for input/output per $\mathrm{m}^{3}$ of treated wastewater

\section{$\underline{\text { DISCUSSION }}$}

The analysis investigates the environmental impacts of the measures by means of an LCA and then assigns relative weights of abatement importance (shadow prices) to each of the impacts. This facilitates: the ranking of impacts according to the present and future emission goals of the Dutch society; the relative ranking of the performance of each of the measures - through a single monetary indicator; and the prioritisation of efforts with regards to reducing environmental impacts for the decision maker (WdD in this case).

The life cycle evaluation of various impact categories allows for an investigation of the environmental impacts of each measure at the global scale. The environmental performance of the measures, compared against each other, seems to be fairly consistent during the uncertainty analysis. The applied ranges of $[-25 \%$ to $+25 \%]$ on the use of aluminium sulphate, electricity, sludge production and effluent do not appear to alter the relative performance of the four measures. More specifically, while measures C (sand filter) and D (storage tanks) have reduced 
340 outputs to water, their high use of materials - mainly aluminium sulphate and methanol - cause

341 them to have the poorest overall environmental performance. The overall impacts from

342 construction have appeared to be relatively low (less than $2 \%$ ). Had salvage values of equipment

343 and infrastructure not been accounted for, construction impacts would increase (at most by a

344 factor of 3 for the case of civil constructions). Given the relatively low impacts however, this is

345 not expected to affect the results of the analysis.

346 This issue brings about an obvious comparison between the use of such materials like 347 aluminium sulphate and electricity and nutrient outputs to water. With the employment of 348 shadow prices this task is facilitated, as the single monetary indicator allows for a direct 349 comparison per $\mathrm{m}^{3}$ of wastewater. Nonetheless, evaluating the trade-offs after the impacts have 350 been weighted to the same unit simplifies the comparison between the two. The use of a 351 monetary unit allows for their comparison with other aspects of operation and other economic 352 activities $^{19}$ : for example, one can compare the environmental damage induced by the electricity 353 required per $\mathrm{m}^{3}$ of wastewater (now estimated in $€$ ) with the environmental damage induced by 354 emitted pollutants per $\mathrm{m}^{3}$ of wastewater (also estimated in $€$ ) and the actual market price paid to 355 purchase the electricity. The much higher environmental cost of aluminium sulphate and 356 electricity used per $\mathrm{m}^{3}$ of wastewater in comparison to the environmental cost induced by 357 phosphorus and ammonium per $\mathrm{m}^{3}$ of wastewater can be very valuable information to prioritise 358 operational decisions for the system. In the case of using alternative chemicals in place of 359 aluminium sulphate or a different electricity mix with more renewable sources of energy, this 360 trade-off and prioritisation would expectedly change.

361 With regards to the shadow prices used, it should be noted that they stem from both abatement 362 efforts put into each environmental impact (Set 1) and estimated environmental damage costs 
363 brought about by each impact (Sets 2 and 3). That is to say that Set 1 represents costs with 364 regards to how the society whence they are estimated and its policy perceive them to be; Sets 2 365 and 3 represent costs with regards to the value of environmental damage. Arguably, if 366 sustainability is to be achieved, environmental policy should aim to equate the two and therefore 367 reach an 'optimal' level of pollution where abatement equals damage. By example of one of the 368 most significant impact categories in this study (HT) its shadow price value used is $2.51 € / \mathrm{kg} 1,4$ 369 DBeq. emitted to air for year 2014. The reported values based on damage costs are 0.022 and $3700.042 € / \mathrm{kg} 1,4-\mathrm{DB}$ eq. emitted to air for year 2014. Differences between the two damage-costs 371 sets are also observed in the categories of CC, TA and HT. These discrepancies are attributed 372 either to abatement costs being significantly higher than the damage costs generated with the 373 release of some pollutants, due to the fact that future costs of Set 3 are not discounted ${ }^{23}$ or due to 374 the generally great uncertainty surrounding the valuation of some categories, particularly the HT 375 category $^{45}$.

376 Measures B and D have already been investigated in previous studies of the system ${ }^{3-6}$ with two 377 principal aims: target the depletion of DO in the river for critical fauna species and reduce the 378 release of CSOs. The studies have found significant improvements in reducing DO depletion in 379 the river with the application of the river aeration measure (B), which showed clear advantages 380 over the other measures ${ }^{6}$. However, the investigation of the environmental benefits provided by 381 this measure is still limited when applying LCA, even when the most affected sections of the 382 stream are included within the evaluation boundaries. This is mainly due to the fact that the 383 impacts of DO depletion, particularly for river biodiversity, are not accounted for in LCAs. Even 384 though attempts to develop and include biodiversity aspects in LCA have been on-going for 385 more than a decade now, standardised methodologies are still in their primal stages ${ }^{11,46}$. Studies 
386 taking into account local specific conditions and characteristics of the receiving medium have 387 not been very apparent in the literature - arguably due to limitations of this methodological 388 framework ${ }^{45,47}$ : impacts are regarded as generic in space, aggregated over long time horizons, 389 strongly dependent on the chosen functional unit, and with distinct impact pathways so as to 390 avoid double counting. Even though new approaches are being developed to improve on the 391 resolution of geographical and temporal scales of characterisation factors, no general consensus 392 has been reached yet ${ }^{11}$. In these efforts for improved regionalisation of life cycle impacts, 393 deterministic modeling of the systems can be a valuable tool. As previously mentioned, to the 394 best of our knowledge, we consider this the first LCA study for an UWS that employs a 395 deterministic integrated model taking into account hydraulics as well as biochemical processes of 396 the whole system.

397 Inherent limitations to the modeling process of UWSs also exist, mainly regarding model 398 uncertainty or the lack of certain processes in the WWTP and the sewer (e.g. $\mathrm{N}_{2} \mathrm{O}$ production) or 399 pollutants (e.g. micro-pollutants) in current tools. This is mainly due to the fact that there is not 400 yet a general consensus on a deterministic model for these processes. Modeling uncertainty for 401 this integrated model and system has already been studied during other studies ${ }^{6,48}$ on the same 402 system. The inclusion of additional processes and pollutants would expectedly increase the 403 estimated impacts, particularly in the Climate Change (CC) category with added greenhouse gas 404 emissions and in the toxicity categories with the inclusion of micro-pollutants and heavy metals. 405 Furthermore, the emission of suspended solids has demonstrated a reduction with the application 406 of measures A and D during the analysis. However as no characterisation factor was available 407 these loads were not taken into account during the impact assessment. 
408 On these grounds, this investigation is meant to complement the other studies performed for 409 this particular UWS, principally looking into the most cost-effective upgrades to reach qualities 410 set by the EU Water Framework Directive (WFD) at the Dommel River ${ }^{6}$. Measure B (river 411 aeration) has a clear advantage in this respect ${ }^{6}$ (most cost-effective reduction of DO depletion 412 and $\mathrm{NH}_{4}^{+}$peaks). On the other hand, measure D (storage tanks) with its significantly higher costs 413 and poor performance with regards to the WFD objectives ${ }^{6}$ is clearly inferior to the other 414 measures - a result also supported by the outcomes of the LCA presented in this study. Exact 415 cost figures cannot be provided at this moment, but preliminary cost estimates indicate that the 416 installation of the sand filter (measure C) and the deepening of secondary clarifiers (measure A) 417 have costs of the same magnitude, yet significantly lower investment costs than measure D and 418 slightly higher than the installation of river aerators (measure B).

419 The results of this analysis are meant to complement the investigations for the identification of 420 the most appropriate measure with weighted life cycle impacts of each of the options. The use of 421 shadow prices to weight the impact categories simplifies the process of prioritising for the water 422 management agency as costly and time-consuming methods of gauging social perceptions are 423 avoided.

425 ACKNOWLEDGEMENTS

426 The authors would like to acknowledge the People Programme (Marie Curie Actions) of the 427 European Union's Seventh Framework Programme FP7/2007e2013 under REA agreement 428289193 (SANITAS ITN). The authors thank the Spanish Ministry of Science and Innovation 429 (Ramon y Cajal RYC-2013-14595 and CTM 2015-66892-R) and the European Union (Marie 430 Curie Career Integration Grant PCIG9-GA-2011-293535). The authors also acknowledge support 
431 from the Economy and Knowledge Department of the Catalan Government through the

432 Consolidated Research Group (2014-SGR-1168)-LEQUIA-University of Girona and (2014 SGR

433 291)-Catalan Institute for Water Research. This article reflects only the authors' views and the

434 European Union is not liable for any use that may be made of the information contained therein.

SUPPORTING INFORMATION

Supporting information includes: inventory tables for sludge treatment (dewatering and

(S4), description of impact categories used in LCA (S5), characterisation factors used during the

441 were obtained (S7) and annual average rate of change of the Harmonised Index of Consumer

442 Prices (HICP) (S8). This information is available free of charge via the Internet at

443 http://pubs.acs.org/.

(1) OECD. Cost-Benefit Analysis and the Environment; Organisation for Economic Cooperation and Development: Paris, 2006.

(2) Macleod, C. J. A.; Haygarth, P. M. Integrating water and agricultural management under climate change. Sci. Total Environ. 2010, 408 (23), 5619-5622.

(3) Weijers, S. R.; de Jonge, J.; Van Zanten, O.; Benedetti, L.; Langeveld, J.; Menkveld, H. W.; Van Nieuwenhuijzen, A. F. KALLISTO: Cost effective and integrated optimization of the urban wastewater system Eindhoven. Water Pract. Technol. 2012, 7 (2).

(4) Langeveld, J. G.; Schilperoort, R. P. S.; Weijers, S. R. Climate change and urban wastewater infrastructure: There is more to explore. J. Hydrol. 2013, 476 (0), 112-119.

(5) Langeveld, J. G.; Benedetti, L.; de Klein, J. J. M.; Nopens, I.; Amerlinck, Y.; van Nieuwenhuijzen, A.; Flameling, T.; van Zanten, O.; Weijers, S. Impact-based integrated real-time control for improvement of the Dommel River water quality. Urban Water J. 2013, 10 (5), 312-329.

(6) Benedetti, L.; Langeveld, J.; van Nieuwenhuijzen, A. F.; de Jonge, J.; de Klein, J.; Flameling, T.; Nopens, I.; van Zanten, O.; Weijers, S. Cost-effective solutions for water 
461

462

463

464

465

466

467

468

469

470

471

472

473

474

475

476

477

478

479

480

481

482

483

484

485

486

487

488

489

490

491

492

493

494

495

496

497

498

499

500

501

502

503

504

505

quality improvement in the Dommel River supported by sewer-WWTP-river integrated modelling. Water Sci. Technol. 2013, 68 (5), 965.

(7) Devesa, F.; Comas, J.; Turon, C.; Freixó, A.; Carrasco, F.; Poch, M. Scenario analysis for the role of sanitation infrastructures in integrated urban wastewater management. Environ. Model. Softw. 2009, 24 (3), 371-380.

(8) Corominas, L.; Acuña, V.; Ginebreda, A.; Poch, M. Integration of freshwater environmental policies and wastewater treatment plant management. Sci. Total Environ. 2013, 445-446, 185-191.

(9) ISO. Environmental Management: Life Cycle Assessment: Principles and Framework; International Organization for Standardization, 2006; Vol. 14040.

(10) Corominas, L.; Foley, J.; Guest, J. S.; Hospido, A.; Larsen, H. F.; Morera, S.; Shaw, A. Life cycle assessment applied to wastewater treatment: State of the art. Water Res. 2013, 47 (15), 5480-5492.

(11) Loubet, P.; Roux, P.; Loiseau, E.; Bellon-Maurel, V. Life cycle assessments of urban water systems: A comparative analysis of selected peer-reviewed literature. Water Res. 2014, 67, 187-202.

(12) El-Sayed Mohamed Mahgoub, M.; van der Steen, N. P.; Abu-Zeid, K.; Vairavamoorthy, K. Towards sustainability in urban water: a life cycle analysis of the urban water system of Alexandria City, Egypt. J. Clean. Prod. 2010, 18 (10-11), 1100-1106.

(13) Meneses, M.; Pasqualino, J. C.; Castells, F. Environmental assessment of urban wastewater reuse: Treatment alternatives and applications. Chemosphere 2010, 81 (2), 266-272.

(14) Morera, S.; Comas, J.; Poch, M.; Corominas, L. Connection of neighboring WWTPs: economic and environmental assessment. J. Clean. Prod. 2015, 90, 34-42.

(15) Loubet, P.; Roux, P.; Núñez, M.; Belaud, G.; Bellon-Maurel, V. Assessing Water Deprivation at the Sub-river Basin Scale in LCA Integrating Downstream Cascade Effects. Environ. Sci. Technol. 2013, 47 (24), 14242-14249.

(16) Renou, S.; Thomas, J. S.; Aoustin, E.; Pons, M. N. Influence of impact assessment methods in wastewater treatment LCA. J. Clean. Prod. 2008, 16 (10), 1098-1105.

(17) Fougerit, V.; Auclair, P.; Bonhoure, S. Monetary weighting of LCA results to integrate a two-stage management system in the decision process. In Proceedings 2 nd LCA Conference; 2012; Vol. 6, p 7.

(18) Huppes, G.; Oers, L. van. Background Review of Existing Weighting Approaches in Life Cycle Impact Assessment (LCIA).; JRC Scientific and Technical Reports; Publications Office of the European Union: Luxembourg, 2011.

(19) Wu, X.; Zhang, Z.; Chen, Y. Study of the environmental impacts based on the "green tax"- applied to several types of building materials. Build. Environ. 2005, 40 (2), 227237.

(20) Guinée, J. B.; Gorrée, M.; Heijungs, R.; Huppes, G.; Kleijn, R.; Koning, A.; Oers, L. van; Wegener Sleeswijk, A.; Suh, S.; Udo de Haes, H. A.; et al. Handbook on Life Cycle Assessment - Operational Guide to the ISO Standards; Eco-Efficiency in Industry and Science; Kluwer Academic Publishers: Dordrecht, The Netherlands, 2001; Vol. 7.

(21) Harmelen, T. van; Korenrompa, R.; Deutekomb, C. van; Ligthart, T.; Leeuwenc, S. van; Gijlswijk, R. van. The price of toxicity. Methodology for the assessment of shadow prices for human toxicity, ecotoxicity and abiotic depletion. In Quantified Eco-Efficiency; 
Huppes, G., Ishikawa, M., Eds.; Eco-Efficiency in Industry and Science; Springer Netherlands, 2007; pp 105-125.

(22) Finnveden, G. A Critical Review of Operational Valuation/Weighting Methods for Life Cycle Assessment; AFR-REPORT 253; Swedish Environmental Protection Agency: Stockholm, Sweden, 1999.

(23) Ahlroth, S.; Nilsson, M. ans; Finnveden, G.; Hjelm, O.; Hochschorner, E. Weighting and valuation in selected environmental systems analysis tools-suggestions for further developments. J. Clean. Prod. 2011, 19 (2), 145-156.

(24) Eldh, P.; Johansson, J. Weighting in LCA Based on Ecotaxes - Development of a Midpoint Method and Experiences from Case Studies. Int. J. Life Cycle Assess. 2006, 11 (1), 81-88.

(25) de Bruyn, S.; Korteland, M.; Markowska, A.; Davidson, M.; de Jong, F.; Bles, M.; Sevenster, M. Shadow Prices Handbook: Valuation and weighting of emissions and environmental impacts; CE Delft: Delft, the Netherlands, 2010.

(26) Howarth, A.; Pearce, D. W.; Ozdemiroglu, E.; Seccombe-Hett, T.; Wieringa, K.; Streefkerk, C. M.; De Hollander, A. E. M. Valuing the benefits of environmental policy: The Netherlands; RIVM report 481505024; 2001; p 194.

(27) Vos, S.; Joehen, G.; Cvert, M.; others. LCA of thermal treatment of waste streams in cement clinker kilns in Belgium Comparison to alternative treatment options; I\&T AR 2007/036, Apeldoom, Netherlands: TNO Institute of Environmental Sciences, Netherlands Organization for Applied Scientific Research. 8-40, 2007.

(28) Bateman, I. J.; Cole, M. A.; Georgiou, S.; Hadley, D. J. Comparing contingent valuation and contingent ranking: A case study considering the benefits of urban river water quality improvements. J. Environ. Manage. 2006, 79 (3), 221-231.

(29) Del Saz-Salazar, S.; Hernández-Sancho, F.; Sala-Garrido, R. The social benefits of restoring water quality in the context of the Water Framework Directive: A comparison of willingness to pay and willingness to accept. Sci. Total Environ. 2009, 407 (16), 45744583.

(30) Birol, E.; Karousakis, K.; Koundouri, P. Using economic valuation techniques to inform water resources management: A survey and critical appraisal of available techniques and an application. Sci. Total Environ. 2006, 365 (1-3), 105-122.

(31) Boyle, K. J.; Desvousges, W. H.; Johnson, F. R.; Dunford, R. W.; Hudson, S. P. An Investigation of Part-Whole Biases in Contingent-Valuation Studies. J. Environ. Econ. Manag. 1994, 27 (1), 64-83.

(32) Diamond, P. A.; Hausman, J. A. Contingent Valuation: Is Some Number better than No Number? J. Econ. Perspect. 1994, 8 (4), 45-64.

(33) Shabman, L.; Stephenson, K. Environmental Valuation and Its Economic Critics. J. Water Resour. Plan. Manag. 2000, 126 (6), 382-388.

(34) Molinos-Senante, M.; Hernández-Sancho, F.; Sala-Garrido, R. Economic feasibility study for wastewater treatment: A cost-benefit analysis. Sci. Total Environ. 2010, 408 (20), 4396-4402.

(35) Färe, R.; Grosskopf, S.; Weber, W. L. Shadow Prices of Missouri Public Conservation Land. Public Finance Rev. 2001, 29 (6), 444-460.

(36) Pearce, D. W. Economic Values and the Natural World; Earthscan, 1993. 
550 (37) Alp, E.; Melching, C. S. Allocation of supplementary aeration stations in the Chicago 